\title{
EVALUATION OF A PROGRESSIVE FAILURE ANALYSIS METHODOLOGY FOR LAMINATED COMPOSITE STRUCTURES
}

\author{
David W. Sleight*, Norman F. Knight, Jr. ${ }^{\dagger}$, and John T. Wang* \\ NASA Langley Research Center \\ Hampton, VA 23681-0001 \\ Paper for the AIAA/ASME/ASCE/AHS/ASC \\ 38th Structures, Structural Dynamics, and Materials Conference \\ April 7-10, 1997
}

AIAA Paper 97-1187

* Aerospace Engineer, CSB/SD, Member AIAA

$\dagger$ Aerospace Engineering Department, Old Dominion University, Associate Fellow AIAA

Copyright $O 1997$ by the American Institute of Aeronautics and Astronautics, Inc. No copyright is asserted in the United States under title 17, U.S. Code. The U.S. Government has a royalty-free license to exercise all rights under the copyright claimed herein for government puposes. All rights are reserved by the copyright owner. 


\title{
EVALUATION OF A PROGRESSIVE FAILURE ANALYSIS METHODOLOGY FOR LAMINATED COMPOSITE STRUCTURES
}

\author{
David W. Sleight ${ }^{*}$, Norman F. Knight, Jr. ${ }^{\dagger}$, and John T. Wang* \\ NASA Langley Research Center \\ Hampton, VA 23681-0001
}

\begin{abstract}
$\underline{\text { Abstract }}$
A progressive failure analysis methodology has been developed for predicting the nonlinear response and failure of laminated composite structures. The progressive failure analysis uses $\mathrm{C}^{1}$ plate and shell elements based on classical lamination theory to calculate the in-plane stresses. Several failure criteria, including the maximum strain criterion, Hashin's criterion, and Christensen's criterion, are used to predict the failure mechanisms. The progressive failure analysis model is implemented into a general purpose finite element code and can predict the damage and response of laminated composite structures from initial loading to final failure.
\end{abstract}

\section{Introduction}

Composite materials have been increasingly used in aerospace and automotive applications over the last three decades and have seen a dramatic increase in usage in non-aerospace products in the past five years. The use of composite materials is very attractive because of their outstanding strength, stiffness, and light-weight properties. An additional advantage of using composites is the ability to tailor the stiffness and strength to specific design loads. Since most composite materials exhibit brittle failure with little or no ductility, as offered by metals, the behavior of the composite structure must be understood, and analysis methods to predict and propagate the failure need to be developed. Laminated composite structures can develop local failures or exhibit local damage such as matrix cracks, fiber breakage, fiber-matrix debonds, and delaminations under normal operating conditions which may contribute to their premature failure. The ability to predict the initiation and growth of such damage is

\footnotetext{
* Aerospace Engineer, CSB/SD, Member AIAA

$\dagger$ Aerospace Engineering Department, Old Dominion University, Associate Fellow AIA A

Copyright 01997 by the American Institute of Aeronautics and Astronautics, Inc. No copyright is asserted in the United States under title 17, U.S. Code. The U.S. Government has a royalty-free license to exercise all rights under the copyright claimed herein for government purposes. All rights are reserved by the copyright owner.
}

essential for predicting the performance of composite structures and developing reliable, safe designs which exploit the advantages offered by composite materials. Hence, the need for a reliable methodology for predicting failure initiation and propagation in laminated composite structures is of great importance.

In recent years, the progression of damage in composite laminates has been a focus of extensive research. Ochoa and Reddy present an excellent discussion of progressive failure. ${ }^{1}$ Reddy and Pandey ${ }^{2}$ developed a finite element procedure based on first-order shear deformation theory for first-ply failure analysis of laminated composite plates subjected to in-plane and/or transverse loads. Pandey and Reddy ${ }^{3}$ extended their earlier work on first-ply failure of two-dimensional laminated composites to include a progressive failure analysis capability. However, only a linear finite element analysis was performed. Reddy and Reddy ${ }^{4}$ calculated and compared the first-ply failure loads obtained by using both linear and nonlinear finite element analyses on composite plates. The differences between the linear and nonlinear failure loads were found to be large for the cases of transverse loading, and were considerably less for the cases of in-plane (tensile) loading. Ochoa and Engblom ${ }^{5}$ presented a progressive failure analysis for composite laminates in uniaxial tension using a higher-order plate theory with shear deformable elements. Analyses were performed on a plate subjected to uniaxial tension and to four-point bending. However, comparisons with experimental results were not provided. Engelstad, Reddy, and Knight $^{6}$ investigated the postbuckling response and failure prediction of flat composite unstiffened panels loaded in axial compression using 9-node shear deformable elements. Good correlation between the experimentally obtained and analytically predicted postbuckling responses was observed for deflections and surface strains. Only the maximum stress criterion and the Tsai-Wu criterion were used in the failure predictions. Chamis et al. ${ }^{7}$ presented a damage tolerance model for pressurized cylinders which included damage detection, progression, and failure. Failure criteria and delamination models were assessed and material properties reconstituted. Only analytical simulations 
were presented. Hwang and $\operatorname{Sun}^{8}$ performed a failure analysis of laminated composites by using an iterative three-dimensional finite element method. The threedimensional analytical results agree favorably with the experimental results for notched and unnotched specimens loaded in tension. However, the analytical predictions underestimated the experimental results for angle-plied laminates with holes. Chang and Chang ${ }^{9}$ developed a progressive failure damage model for laminated composites containing stress concentrations. They applied this progressive failure method to bolted composite joints and to a laminated composite plate containing a hole. Comparisons were made to experimental results in these studies and reasonable correlation to the data was reported. In summary, whereas much research has been performed on the progressive failure of structural components undergoing linear deformations, limited research including nonlinear deformations has been done.

The objective of this paper is to examine the use of progressive failure analysis in the nonlinear deformation regime. A progressive failure methodology is developed and implemented into a general purpose finite element code and validated by comparing analytical predictions of progressive failure of geometrically nonlinearly deformed composite structures with experimental data. Different formulation methods for detecting failure are also compared and assessed. This effort incorporates the failure detection and material degradation models of different researchers into a single computational structural mechanics framework. As such, different approaches can be readily compared and new failure and materials models incorporated.

\section{Progressive Failure Methodology}

A typical methodology for a progressive failure analysis is illustrated in Figure 1. At each load step, a nonlinear analysis is performed until a converged solution is obtained assuming no changes in the material model. Then using this equilibrium state, the stresses within each lamina are determined from the nonlinear analysis solution at this step. These stresses are then compared with material allowables or used to assess certain failure theories. A survey of failure criteria is presented by Tan. ${ }^{10}$ If a lamina failure is detected, as indicated by a failure criterion, the lamina properties are changed according to a particular degradation method. Then, the initial nonlinear solution no longer corresponds to an equilibrium state and equilibrium of the structure needs to be reestablished utilizing the modified lamina properties for the failed lamina while maintaining the current load level. This iterative process of obtaining nonlinear equilibrium solutions each time a local material model is changed is continued until no additional lamina failures are detected. The load step is then incremented until catastrophic failure of the structure is detected.

Therefore, typical progressive failure analysis methods involve five key features. First, a nonlinear analysis capability is needed in order to establish equilibrium. Second, an accurate stress recovery procedure is needed in order to establish the local lamina stress state. Third, failure detection criteria are needed in order to detect or sense local lamina failure which may also indicate the nature of the failure. Fourth, material degradation or damage models are needed in order to propagate the failure and establish new estimates for the local material properties. Finally, a procedure to reestablish equilibrium after modifying local lamina properties is needed. This research focuses on the last four features since nonlinear analysis procedures are already well established. The progressive failure methodology developed in this paper is an extension of work performed by Pifko ${ }^{11,12}$ of Northrop-Grumman Aerospace Corporation..

To implement and perform the progressive failure methodology described earlier, a structural analysis software system is needed. The framework to accomplish this task is a structural analysis software system called COMET (COmputational MEchanics Testbed) ${ }^{13,14}$ developed jointly between NASA Langley Research Center and Lockheed Palo Alto Research Laboratory. COMET's capabilities include linear and nonlinear stress analyses of large-scale built-up structures, transient dynamic analyses, and eigenvalue analyses.

The progressive failure analysis methodology uses $\mathrm{C}^{\prime}$ plate and shell elements based on classical lamination theory to calculate the in-plane stresses. The nonlinear Green-Lagrange strain-displacement relations are used in the element formulation, and large rotations are treated through the element-independent corotational formulation in COMET. The progressive failure methodology implemented in COMET accommodates the maximum strain criterion, Christensen's criterion, ${ }^{15}$ and Hashin's criterion. ${ }^{16,17}$ When a failure is detected, the progressive failure model classifies the mode of failure as fiber failure, matrix failure, shear failure, or an interaction of failure modes. 
In the maximum strain criterion, failure is assumed to occur if any of the following conditions are satisfied:

$$
\begin{array}{ll}
\varepsilon_{1} \geq X_{\varepsilon_{T}} \text { or }\left|\varepsilon_{1}\right| \geq X_{\varepsilon_{C}} & \text { fiber failure } \\
\varepsilon_{2} \geq Y_{\varepsilon_{T}} \text { or }\left|\varepsilon_{2}\right| \geq Y_{\varepsilon_{C}} & \text { matrix failure } \\
\left|\gamma_{12}\right| \geq T_{\varepsilon} & \text { shear failure }
\end{array}
$$

where $\varepsilon_{1}, \varepsilon_{2}$, and $\gamma_{12}$ are the lamina strains in the material coordinate system and $X_{\varepsilon_{T}}, X_{\varepsilon_{C}}, Y_{\varepsilon_{T}}$, $Y_{\varepsilon_{C}}$, and $T_{\varepsilon}$ are the material allowable strains denoted as

$X_{\varepsilon_{T}}=$ critical tensile strain in fiber direction

$X_{\varepsilon_{C}}=$ critical compressive strain in fiber direction

$Y_{\varepsilon_{T}}=$ critical tensile strain in matrix direction

$Y_{\varepsilon_{C}}=$ critical compressive strain in matrix direction

$T_{\varepsilon}=$ critical shear strain

The absolute value sign on $\gamma_{12}$ indicates that the sign of the shear strain is assumed to not affect the failure criterion. The maximum strain criterion is a non-interactive failure theory in strain space. Since the maximum strain criterion provides different conditions for failure, the mode of failure can be identified as either fiber failure, matrix failure, or shear failure.

Hashin ${ }^{17}$ proposed a stress-based failure criterion that has the ability to predict the modes of failure. The observation of failure in unidirectional fibrous composites indicates that there are two primary failure modes: a fiber mode in which the composite fails due to fiber breakage in tension or fiber buckling in compression; and a matrix mode in which matrix cracking occurs. Since different failure mechanisms occur in tension and compression, Hashin further subdivided each failure mode into a tension and compression mode. The failure modes are summarized for the case of plane stress as follows:

Tensile Fiber Mode, $\sigma_{1}>0$

$$
\left(\frac{\sigma_{1}}{X_{T}}\right)^{2}+\left(\frac{\tau_{12}}{T}\right)^{2}=1
$$

Compressive Fiber Mode, $\sigma_{1}<0$

$$
\left(\frac{\sigma_{1}}{X_{C}}\right)^{2}=1
$$

Tensile Matrix Mode, $\sigma_{2}>0$

$$
\left(\frac{\sigma_{2}}{Y_{T}}\right)^{2}+\left(\frac{\tau_{12}}{T}\right)^{2}=1
$$

Compressive Matrix Mode, $\sigma_{2}<0$

$$
\frac{\sigma_{2}}{Y_{C}}\left[\left(\frac{Y_{C}}{2 T}\right)^{2}-1\right]+\left(\frac{\sigma_{2}}{2 T}\right)^{2}+\left(\frac{\tau_{12}}{T}\right)^{2}=1
$$

where $\sigma_{1}, \sigma_{2}$, and $\tau_{12}$ are the in-plane lamina stresses and $X_{T}, X_{C}, Y_{T}, Y_{C}$, and $T$ are the lamina strengths. The subscripts $T$ and $C$ in $X$ and $Y$ refer to the normal strengths in tension and compression.

Christensen ${ }^{15}$ introduced a quasi-three-dimensional lamination theory which accounted for the out-of-plane stress terms. In related work, Christensen then proposed a strain-based failure criterion which distinguished the modes of failure into either fiber failure or fiber/matrix interaction failure. The corresponding equations for failure are as follows:

Fiber Failure:

$$
X_{\varepsilon_{C}} \leq \varepsilon_{1} \leq X_{\varepsilon_{T}}
$$

Fiber/Matrix Interaction Failure:

$$
\beta \varepsilon_{k k}+e_{i j} e_{i j} \geq \alpha^{2}
$$

where $\beta$ and $\alpha$ are determined from experimental failure data and $e_{i j}$ is the deviatoric strain tensor given by

$$
e_{i j}=\varepsilon_{i j}-\frac{1}{3} \delta_{i j} \varepsilon_{k k}
$$


In Christensen's analyses, the two parameters $\beta$ and $\alpha$ in Equation (7) are evaluated to fit failure data for tensile and compressive failure with no shear stress.

When a failure is detected, the progressive failure model classifies the mode of failure as fiber failure, matrix failure, or shear failure. Two material degradation models are implemented including instantaneous reduction and gradual reduction of the material properties for use with the ply-discount approach. The material properties which are degraded when a failure is detected depend upon the failure mode. The solution procedure performs a geometrically nonlinear analysis using a modified Newton-Raphson algorithm for either applied force or applied displacement problems. The procedure is also capable of using a global load-stepping algorithm for advancing the nonlinear analysis solution during a static analysis. Equilibrium is not presently re-established in the nonlinear analysis procedure implemented in COMET. Instead, the strategy is to use small load increments in the nonlinear analysis procedure which minimizes the effect of not re-establishing equilibrium as shown in Figure 1.

\section{$\underline{\text { Results }}$}

The progressive failure methodology described earlier has been successfully implemented in COMET. Two examples are considered for the evaluation of the methodology. The first example deals with a composite laminate under rail-shear loading. The second example is a laminated composite panel subjected to an axial compressive load. Numerical results obtained using the present progressive failure methodology are compared with other published results. Additional problems have been solved and are reported by Sleight. ${ }^{18}$

These examples are of interest because of the available experimental data and their applicability to aircraft structures. The first example is a membrane problem with the nonlinear behavior due to material failure. The second example involves combined membrane and bending behavior and combined material degradation and large deflections.

For the models considered, determining the structural response involves several steps using COMET. For the model with compressive loading, the first step is to perform a linear static analysis. Using the linear static analysis, the primary equilibrium path is found which produces no out-of-plane deflection. The next step is a linear stability analysis to find the point at which the primary path will bifurcate to a secondary equilibrium path. Along the secondary path, the transverse deflections will increase. The third step is forming the initial geometric imperfection which serves as a trigger for the geometric nonlinearities. For the model with shear loading, these first three steps are not required since buckling does not occur. For both models, the next step is to perform an elastic nonlinear analysis to understand how the structure behaves without any material failures. Finally, a combined material degradation and geometrically nonlinear analysis is performed which is called a progressive failure analysis. In quantifying the failure state, the percentage of failed plies is used and defined as the number of plies with failures at each Gauss point divided by the product of the number of plies and the number of Gauss points.

\section{Rail-Shear Panel}

Rail-shear tests are frequently used to measure inplane shear strength. The rail-shear specimen used in this analysis is the T300/976 graphite-epoxy cross-ply laminate reported on by Shahid ${ }^{19}$ with both analytical and experimental data.

The material properties of the $\mathrm{T} 300 / 976$ graphiteepoxy used in this analysis are based on the data available in Shahid. ${ }^{19}$ These values include $E_{11}=20.2 \times 10^{6}(\mathrm{psi}), \quad E_{22}=1.41 \times 10^{6}(\mathrm{psi}), \quad G_{12}=$ $0.81 \times 10^{6}$ (psi), and $v_{12}=.29$. Note that $G_{12}$ is a function of the stacking sequence. Based on Shahid, ${ }^{19}$ the material allowable values are $X_{T}=220.0 \times 10^{3}(\mathrm{psi}), X_{C}=231.0 \times 10^{3}(\mathrm{psi}), \quad Y_{T}=$ $6.46 \times 10^{3}$ (psi), $Y_{C}=36.7 \times 10^{3}$ (psi), and in-plane shear strength $T=6.0 \times 10^{3}$ (psi). The 24-ply laminate has a stacking sequence of $\left[0_{6} / 90_{6}\right]_{5}$. The nominal ply thickness is taken as 0.0052 inches.

The specimen is 6-inches long and 1-inch wide. In order to represent the boundary conditions of the specimen in a rail-shear fixture, one edge of the specimen is firmly fixed, while on the other parallel edge, deformations are allowed parallel to the edge in the $y$-direction and restrained from motion in the $x$ direction. Upon loading, a displacement increment is applied along the latter edge. A finite element model of this specimen with 48 4-node elements along the length and 8 4-node elements along the width is shown in Figure 2.

The structural response of the rail-shear specimen is studied. A nonlinear analysis is first performed to 
understand the behavior of the rail-shear specimen without any material failures. Then progressive failure studies are performed on the model to evaluate the three failure criteria on predicting the failure of the panel. For the analyses, an initial displacement of 0.0005 inches is applied to the left edge of the rail-shear specimen. The displacement increment for successive progressive failure analysis load steps is also 0.0005 inches.

A summary of the failure loads (first-ply failure and final failure) and the dominant failure mode type using the three failure criteria is presented in Table 1. Loaddeflection curves presented in Figure 3 compare all criteria with the experimental and analytical results of Shahid. ${ }^{19}$ All progressive failure results agree very well with the experimental results. Figures 4 and 5 show the structural response at selected loads along the loaddeflection curve using Christensen's criterion. The left figures (Figures $4 \mathrm{a}$ and $5 \mathrm{a}$ ) indicate the percentage of failed plies within an element, and the right figures (Figures $4 \mathrm{~b}$ and $5 \mathrm{~b}$ ) depict the $N_{x y}$ stress resultant distribution. Dark regions indicate high values. These figures show the development of damage and its propagation to failure. The progressive failure analyses using other criteria show similar structural responses. The laminate fails along the edges of the panel where the shear loading is applied.

\section{Compression-Loaded Composite Panel}

The next example is a composite rectangular panel loaded in axial compression. The panel length is 20.0 inches and the width is 6.75 inches. This panel is denoted Panel C4 in the experimental results reported by Starnes and Rouse. ${ }^{20}$

The panel is fabricated from unidirectional Thornel 300 graphite-fiber tapes preimpregnated with $450 \mathrm{~K}$ cure Narmco 5208 thermosetting epoxy resin. The material properties of the specimen are based on the data available from the test. ${ }^{20}$ The values include $E_{11}=$ $19.0 \times 10^{6}(\mathrm{psi}), \quad E_{22}=1.89 \times 10^{6}(\mathrm{psi}), \quad G_{12}=$ $0.93 \times 10^{6}$ (psi), and $v_{12}=.38$. From Engelstad's paper, ${ }^{6}$ the material allowable values are $X_{T}=200.0 \times 10^{3}(\mathrm{psi}), \quad X_{C}=165.0 \times 10^{3}$ (psi), $Y_{T}=11.74 \times 10^{3}$ (psi), $\quad Y_{C}=27.41 \times 10^{3}(\mathrm{psi}), \quad$ and in-plane shear strength $T=10.0 \times 10^{3}$ (psi). The panel used is a 24-ply orthotropic layup with a $\left[ \pm 45 / 0_{2} / \pm 45 / 0_{2} / \pm 45 / 0 / 90\right]_{s}$ stacking sequence.

The thickness of each ply is 0.00535 inches.
The finite element model of this panel shown in Figure 6 has 40 4-node elements along the length and 14 4-node elements along the width. The loaded ends of the panel are clamped by fixtures, and the unloaded ends are simply supported by knife-edge supports to prevent the panel from buckling as a wide column.

The structural response of the $\mathrm{C} 4$ panel is studied. A fringe plot of the first buckling mode from the linear stability analysis is shown in Figure 7a and compared to the moiré-fringe plot from the experiment ${ }^{20}$ shown in Figure $7 \mathrm{~b}$. The results indicate that the first buckling mode from the analysis and the experimentally observed buckling mode shape are in agreement with each other. The first buckling mode has two longitudinal halfwaves with a buckling node line at panel midlength. An initial geometric imperfection is formed by using the first buckling mode shape normalized by its maximum component, then scaled by $5 \%$ of the panel thickness, and added to the nodal coordinates. The initial displacement applied to the panel is 0.001 inches. A displacement increment of 0.0025 inches is used for the first 10 steps in the progressive failure analysis. Then, a smaller increment of 0.001 inches is chosen for the next 5 load steps so the analysis can pass the buckling load. In the next 25 load steps, a displacement increment of 0.0025 inches is used for the analysis. Finally, a displacement increment of 0.001 inch is used until ultimate failure of the panel is predicted. This adjustment of the applied displacement is done to reduce errors potentially introduced by not reestablishing equilibrium after material degradation.

Progressive failure analyses using Hashin's and Christensen's criteria were performed on the $\mathrm{C} 4$ panel. Similar progressive failure analyses have also been performed by Engelstad, Reddy, and Knight. ${ }^{6}$ The progressive failure results for the $\mathrm{C} 4$ panel are presented in Figures 8 and 9 using Hashin's and Christensen's criteria. The experimental and analytical out-of-plane deflections near a point of maximum deflection are shown in Figure 8 as a function of the applied load and correlate reasonably well. A comparison of analytical and experimental end shortening results as a function of the applied load is shown in Figure 9. The progressive failure results for end shortening also agree reasonably well with the experimental results.

At some point in the progressive failure analysis, a dramatic change in the slope of the end shortening curve indicates an inability for the panel to support any additional load. This load level is designated as the analytical failure load, and the final experimental data point is called the test failure load. The final failure 
loads predicted by both criteria are very close to each other. However, the first-ply failure (FPF) load of Christensen's criterion is much lower than Hashin's criterion. Both failure criteria predicted higher failure loads than the results from the experiment. Table 2 provides a summary of the failure loads (first-ply failure and final failure) and the dominant failure mode type for both failure criteria and the test results. The dominant failure mode of Christensen's criterion is fiber/matrix interaction, and the dominant mode of Hashin's criterion is failure in matrix tension. Starnes and Rouse ${ }^{20}$ reported that the experimental failure mode was due to transverse shear effects at the nodal line of the buckle pattern near panel midlength as a result of coupling of large out-of-plane deflections and high transverse shear strains near the edges of the panel. Engelstad et al. ${ }^{6}$ analytically confirmed this behavior. The current progressive failure analysis capability does not include a transverse shear failure mode, thus, these analytical results cannot predict this failure mode, but still agree reasonably well with the test results. In the future, interlaminar stress predictions will be included in the COMET formulation to predict interlaminar failures.

The structural response of the $C 4$ panel at selected loads (see Figure 9) is given in Figures 10 and 11 using Hashin's criterion. Figures 12 and 13 show the structural response at selected loads using Christensen's criterion. Each set of figures displays the percentage of failed plies within an element, the $N_{x}$ stress distribution, and the out-of-plane deflection of selected steps in the progressive failure analysis. This sequence of figures shows the development of damage and its propagation to final failure. The results show that the damage is concentrated along the nodal line just as the test results indicated in reference 20 . The out-of-plane deflection pattern exhibits large deflections (nearly three times the panel thickness at the buckle crest) and high local gradients. The high in-plane membrane stress resultants and their gradients near the buckle nodal line contribute to the failure propagation and final failure. The in-plane normal and shear stresses interact for the Hashin and Christensen criteria. Examination of the twisting moment resultant $M_{x y}$ shown in Figure $14 \mathrm{~b}$ indicates that near the failure locations high $M_{x y}$ values exist. High $M_{x y}$ values produce high shear stresses $\tau_{x y}$ in the region where the failures occurred. This effect is compounded by high compressive stresses $N_{x}$ shown in Figure $11 \mathrm{~b}$ and contributes to understanding this type of failure.

\section{Concluding Remarks}

A progressive failure methodology has been developed, extended, and successfully implemented in COMET. The current progressive failure methodology uses $C^{1}$ plate and shell elements based on classical lamination theory. The progressive failure methodology accommodates various formulations in predicting failure such as the maximum strain criterion, Hashin's criterion, and Christensen's criterion. These different formulation methods are compared and assessed by performing analyses on laminated composite structures. Results indicate good comparisons with existing test data on two laminated composite panels.

To accomplish a progressive failure analysis tool capable of predicting all types of failures, the current progressive failure methodology should be enhanced. The first enhancement is to extend the current progressive failure model such that it would include failure criteria to predict failure mechanisms involving interlaminar stresses. One option to accomplish this using the current progressive failure model is to calculate the interlaminar stresses $\left(\sigma_{x z}, \sigma_{y z}, \sigma_{z z}\right)$ by integration of the 3-D equilibrium equations. Another option is to incorporate the new shell element by Tessler $^{21}$ which includes the interlaminar stresses as part of the element formulation. Once the interlaminar stresses are known, other failure mechanisms to predict debonding or delaminations could be added. Another enhancement is to extend the progressive failure analysis model so that static equilibrium is reestablished after material properties have been degraded. This is accomplished by repeating the nonlinear analysis at the current load step until a converged solution exists. Such a capability permits the use of arbitrary step sizes during the nonlinear analysis and provides for an automatic step size control rather than fixed step size.

\section{References}

1. Ochoa, O., and Reddy, J. N., Finite Element Analysis of Composite Laminates, Kluwer Academic Publishers, Dordrecht, The Netherlands, 1992.

2. Reddy, J. N., and Pandey, A. K., "A First-Ply Failure Analysis of Composite Laminates," Computers and Structures, Vol. 25, 1987, pp. 371-393. 
3. Pandey, A. K., and Reddy, J. N., "A Post First-Ply Failure Analysis of Composite Laminates," AIAA Paper 87-0898, Proceedings of the AIAA/ASME/ASCE/AHS/ASC 28th Structures, Structural Dynamics, and Materials Conference, 1987, pp. 788-797.

4. Reddy, Y. S., and Reddy, J. N., "Linear and Nonlinear Failure Analysis of Composite Laminates with Transverse Shear," Composites Science and Technology, Vol. 44, 1992, pp. 227-255.

5. Ochoa, O. O., and Engblom J. J., "Analysis of Failure in Composites," Composites Science and Technology, Vol. 28, 1987, pp. 87-102.

6. Engelstad, S. P., Reddy, J. N., and Knight, N. F., Jr., "Postbuckling Response and Failure Prediction of Graphite-Epoxy Plates Loaded in Compression," AIAA Journal, Vol. 30, No. 8, August 1992, pp. 2106-2113.

7. Chamis, C. G., Gotsis P. K., and Minnetyan L., "Damage Tolerance of Composite Pressurized Shells," AIAA Paper AIAA-96-1556-CP, Proceedings of the AIAA/ASME/ASCE/AHS/ASC 37th Structures, Structural Dynamics, and Materials Conference, 1996, pp. 2112-2121.

8. Hwang, W. C., and Sun, C. T., "Failure Analysis of Laminated Composites by Using Iterative Three-Dimensional Finite Element Method," Computers and Structures, Vol. 33, No. 1, 1989, pp. 41-47.

9. Chang, F. K., and Chang, K. Y., "A Progressive Damage Model for Laminated Composites Containing Stress Concentrations," Journal of Composite Materials, Vol. 21, September 1987, pp. 834-855.

10. Tan, S. C., Stress Concentrations in Laminated Composites, Technomic Publishing Co., Lancaster, PA, 1994.

11. Pifko, A. B., and Crouzet-Pascal, J., "Composite Finite Elements in Dycast," Computational Structural Mechanics Review of Contract, Grant, and In-House Research, NASA Langley Research Center, Nancy Sykes (Compiler), August 1989.
12. Pifko, A. B., and Kushner, A. S., "Impact Analysis of Composite Aircraft Structures," Computational Methods for Crashworthiness, Ahmed K. Noor and Huey D. Carden (Compilers), NASA CP-3223, 1993.

13. Knight, N. F., Jr., Gillian, R. E., McCleary, S. L., Lotts, C. G., Poole, E. L., Overman, A. L., and Macy, S. C., CSM Testbed Development and Large-Scale Structural Applications, NASA TM4072, 1989.

14. Stewart, C. B., The Computational Mechanics Testbed User's Manual, NASA TM-100644, October 1989.

15. Christensen, R. M., "Tensor Transformations and Failure Criteria for the Analysis of Fiber Composite Materials," Joumal of Composite Materials, Vol. 22, September 1988, pp. 874-897.

16. Hashin, Z., "Failure Criteria for Unidirectional Fiber Composites," ASME Joumal of Applied Mechanics, Vol. 47, June 1980, pp. 329-334.

17. Hashin, Z., and Rotem, A., "A Fatigue Failure Criterion for Fiber Reinforced Materials," Joumal of Composite Materials, Vol. 7, October 1973, pp. 448-464.

18. Sleight, D. W., "Progressive Failure Analysis of Laminated Composite Structures." MS Thesis, Old Dominion University, Norfolk, VA, August 1996.

19. Shahid, I., "Progressive Failure Analysis of Laminated Composites Subjected to In-Plane Tensile and Shear Loads," Ph. D. Dissertation, Stanford University, Palo Alto, CA, April 1993.

20. Starnes, J. H., Jr., and Rouse, M., "Postbuckling and Failure Characteristics of Selected Flat Rectangular Graphite-Epoxy Plates Loaded in Compression," AIAA Paper 81-0543, April 1981.

21. Tessler, Alexander, and Riggs, Ronald. R., Accurate Interlaminar Stress Recovery from Finite Element Analysis, NASA TM-109149, 1994. 
Table 1 Rail-Shear Panel: Summary of Progressive Failure Results.

\begin{tabular}{|c|c|c|c|}
\hline Failure Criterion & $\begin{array}{l}\text { First-Ply Failure Load } \\
\text { (lbs.) }\end{array}$ & $\begin{array}{l}\text { Final Failure } \\
\text { Load (lbs.) }\end{array}$ & $\begin{array}{c}\text { Dominant Failure } \\
\text { Mode Type }\end{array}$ \\
\hline Christensen & 2105 & 3964 & Fiber-Matrix Interaction \\
\hline Hashin & 2406 & 4016 & Matrix Tension \\
\hline Maximum Strain & 2707 & 4065 & Shear \\
\hline Test Results ${ }^{19}$ & Unavailable & 4010 & Shear \\
\hline
\end{tabular}

Table 2 C4 Panel: Summary of Progressive Failure Results.

\begin{tabular}{|c|c|c|c|}
\hline Failure Criterion & $\begin{array}{c}\text { First Ply Failure Load } \\
\text { (lbs.) }\end{array}$ & $\begin{array}{c}\text { Final Failure } \\
\text { Load (lbs.) }\end{array}$ & $\begin{array}{c}\text { Dominant Failure } \\
\text { Mode Type }\end{array}$ \\
\hline Christensen & 18615 & 22454 & Fiber-Matrix Interaction \\
\hline Hashin & 21778 & 23526 & $\begin{array}{c}\text { Matrix Tension/ } \\
\text { Fiber Compression }\end{array}$ \\
\hline $\begin{array}{c}\text { Engelstad et al. } \\
\text { Maximum Stress }\end{array}$ & 22724 & 25049 & Transverse Shear \\
\hline $\begin{array}{c}\text { Engelstad et al. } \\
\text { Tsai-Wu }\end{array}$ & 20927 & 23464 & Transverse Shear \\
\hline Test Results $^{20}$ & Unavailable & 21910 & Transverse Shear \\
\hline
\end{tabular}




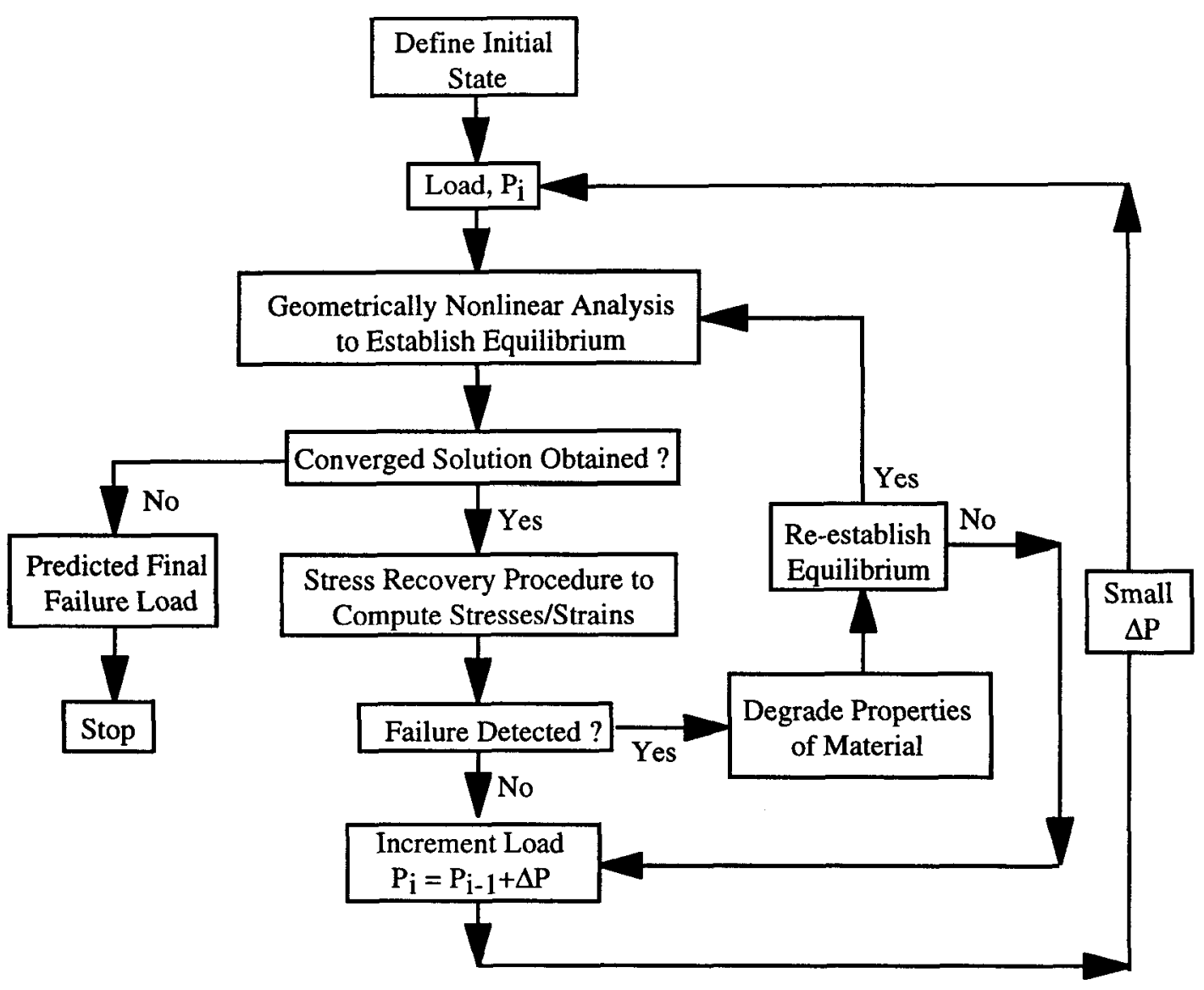

Figure 1 Typical Progressive Failure Analysis Methodology for $i$ th step. 


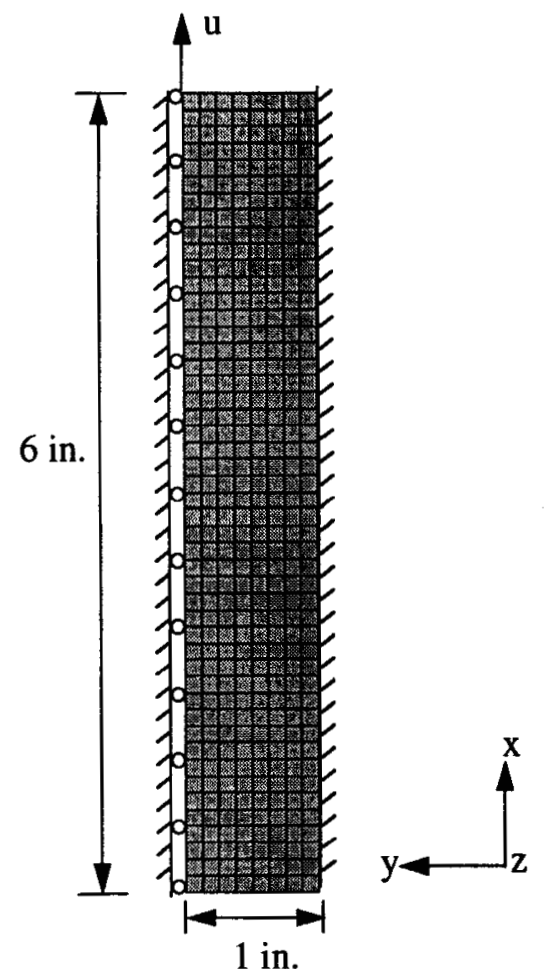

Figure 2 Geometry of Rail-Shear Panel with 48 x 8 Finite Element Mesh.

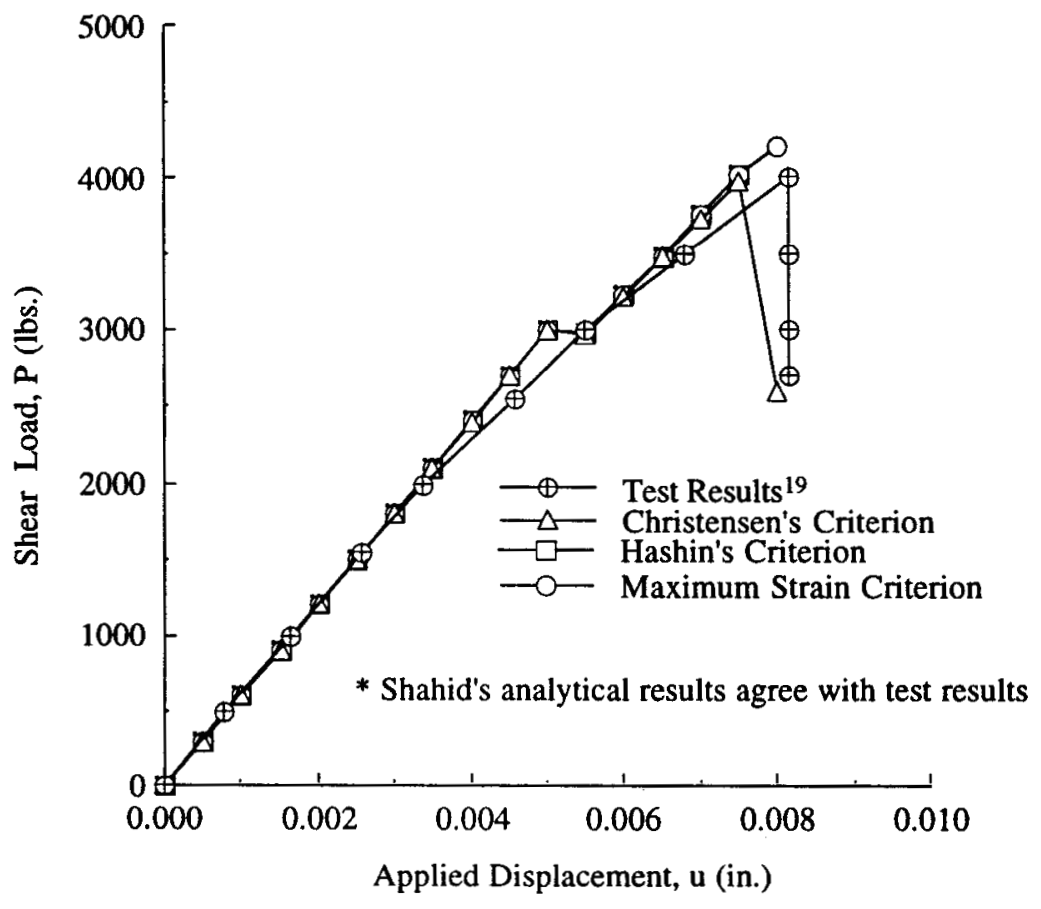

Figure 3 Rail Shear Panel: Load vs. Deflection Response. 


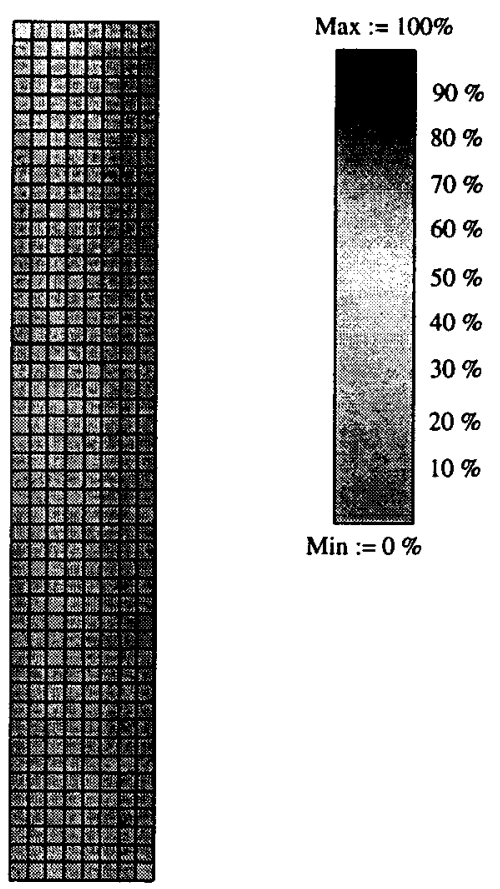

a) Percentage of Failed Plies

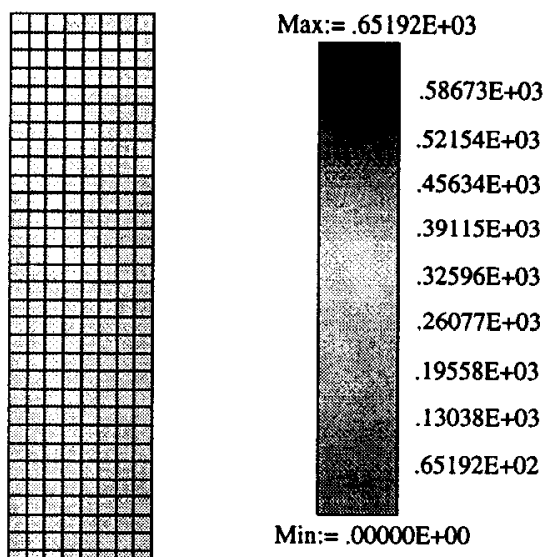

b) $N_{x y}$ Stress Distribution

Figure 4 Rail-Shear Problem: Structural Response at First-Ply Failure (2105 lbs.).

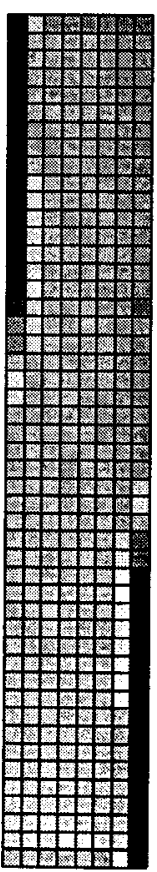

a) Percentage of Failed Plies
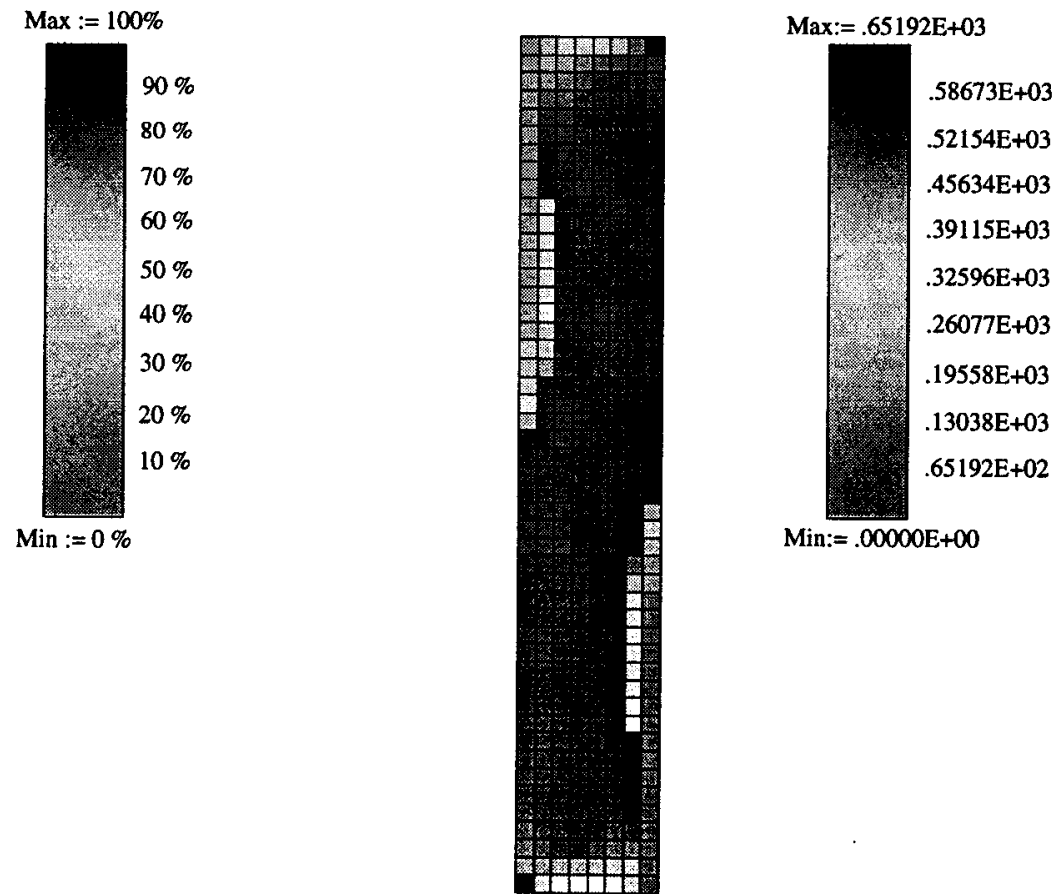

Min: $=.00000 \mathrm{E}+00$

Figure 5 Rail-Shear Problem: Structural Response at Final Failurer(3964 lbs.). 


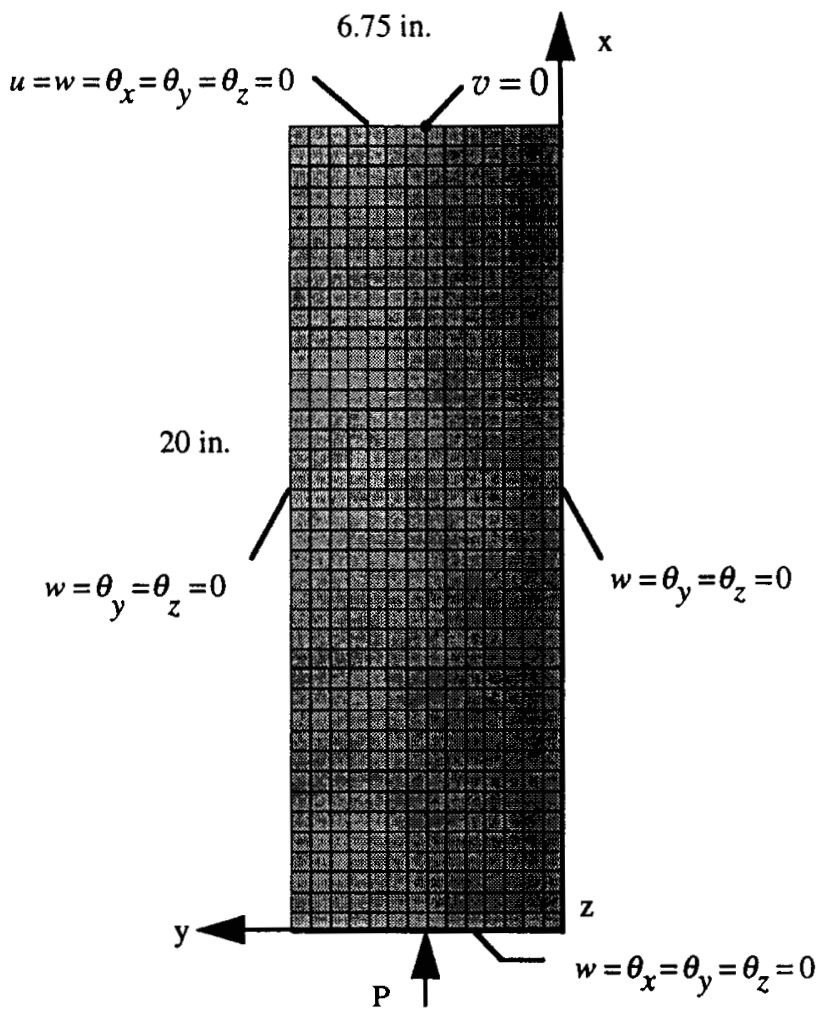

Figure 6 Geometry of C4 Panel.

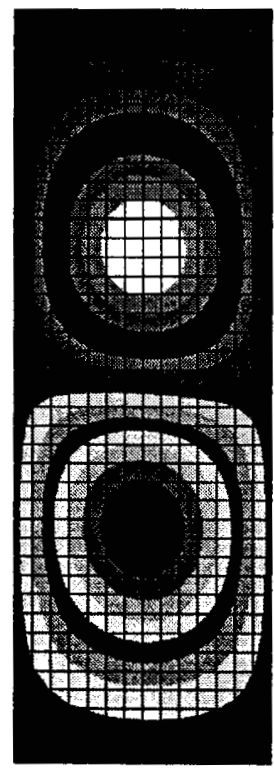

a) Fringe Plot of Analytical Results

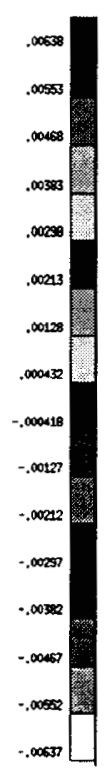

b) Photograph of Moiré-Fringe Pattern from Starnes and Rouse Test ${ }^{20}$

Figure 7 C4 Panel: Comparison of Experimental and Analytical Linear Buckling Mode 1. 


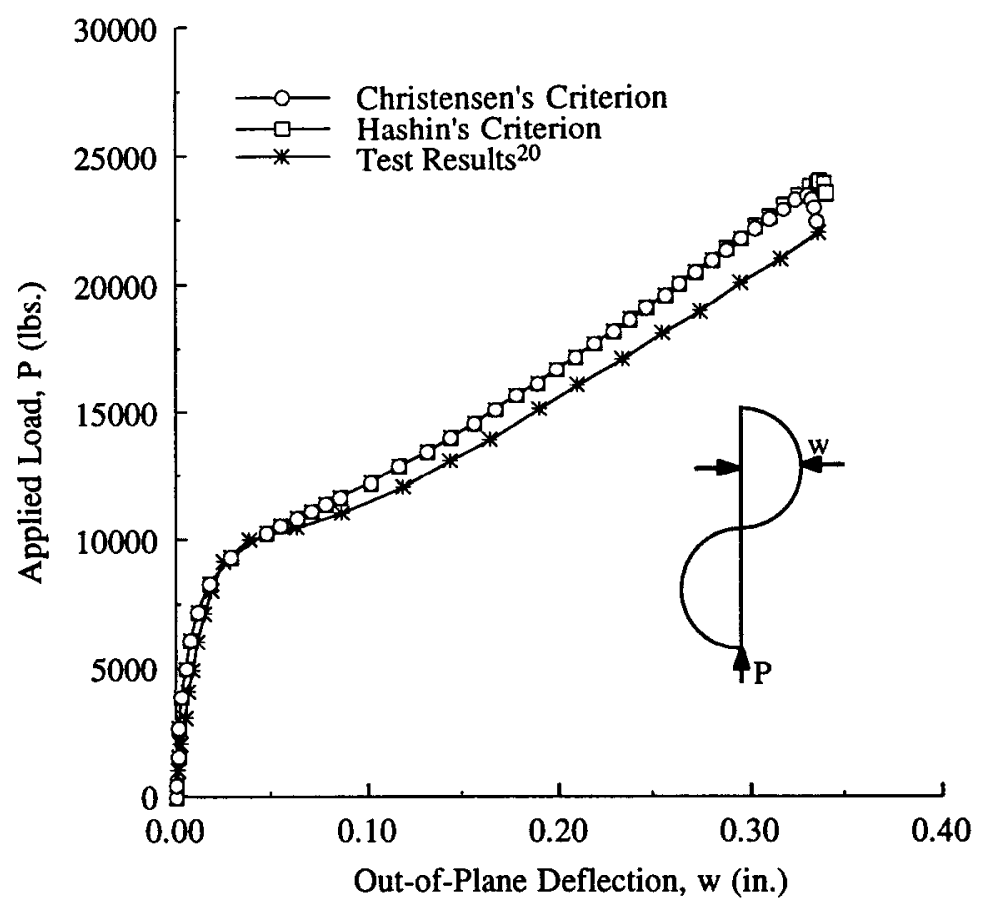

Figure 8 C4 Panel: Out-of-Plane Deflection Comparison.

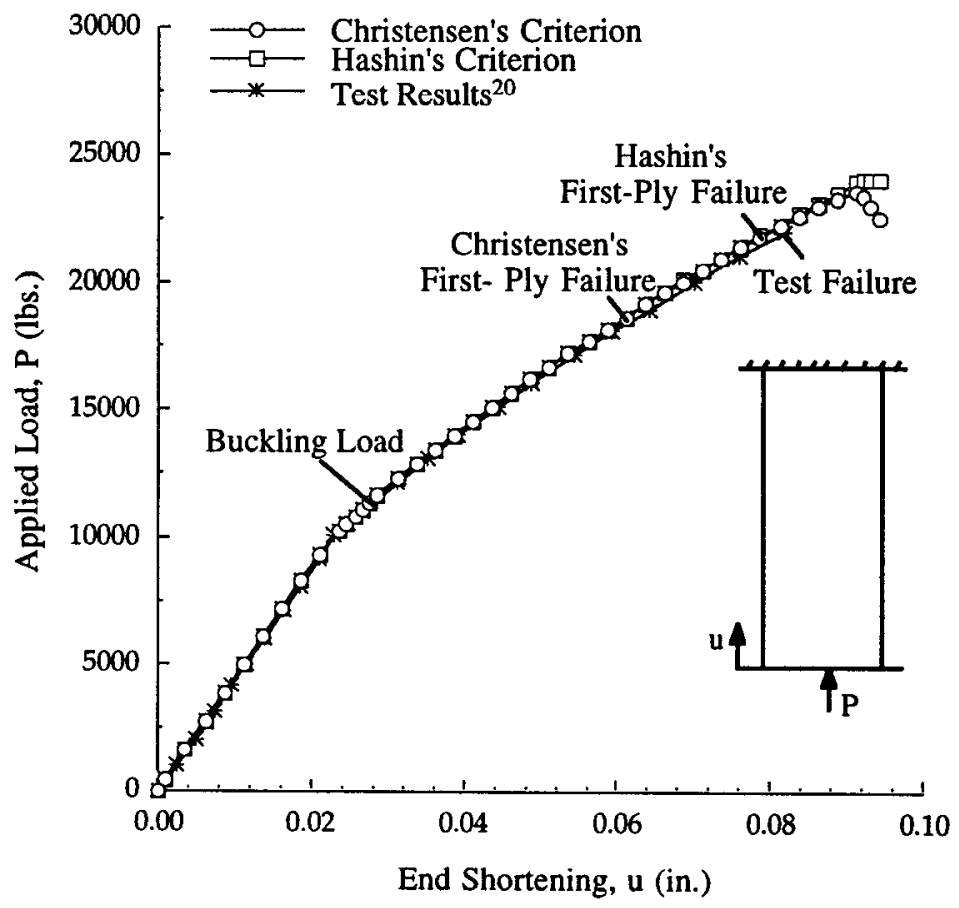

Figure 9 C4 Panel: End-Shortening Comparison 


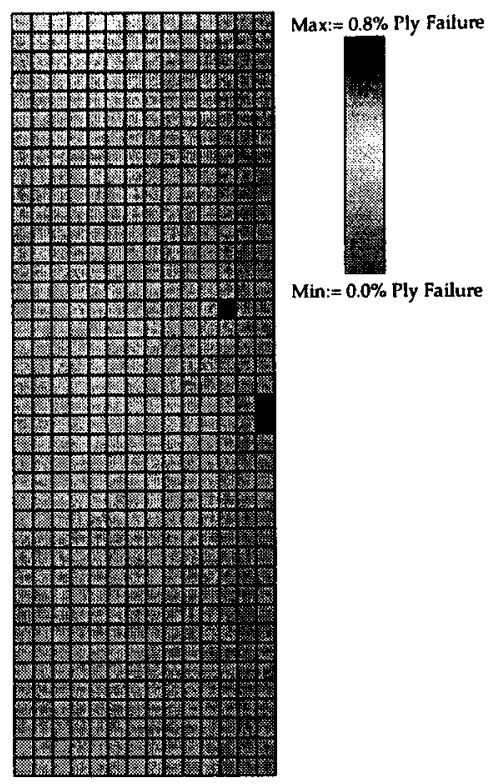

a) Percentage of Failed Plies
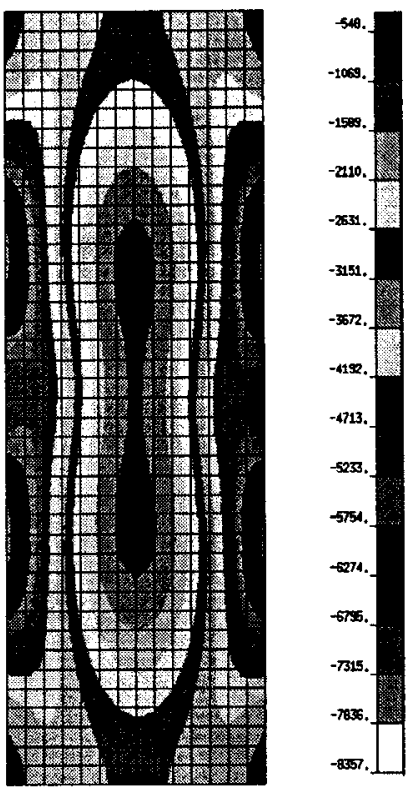

b) $N_{x}$ Stress Distribution
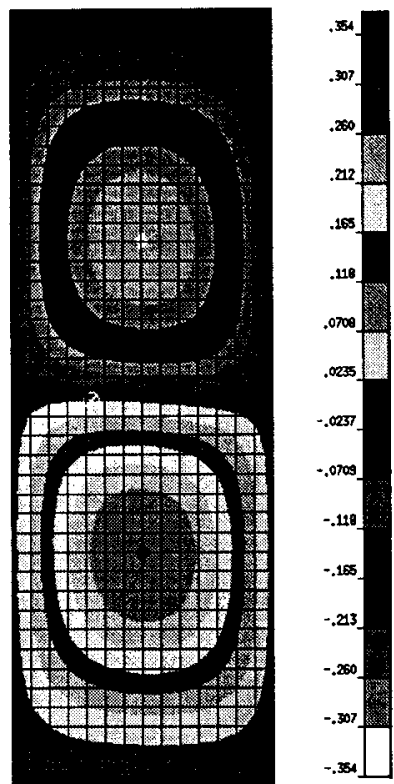

c) Out-of-Plane Deflection

Figure 10 C4 Panel: Structural Response at First-Ply Failure (21778 lbs.) - Hashin's Criterion.
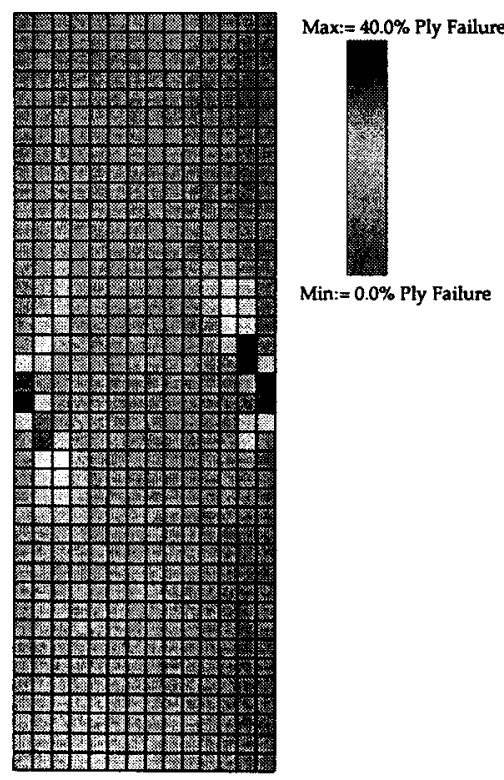

a) Percentage of Failed Plies
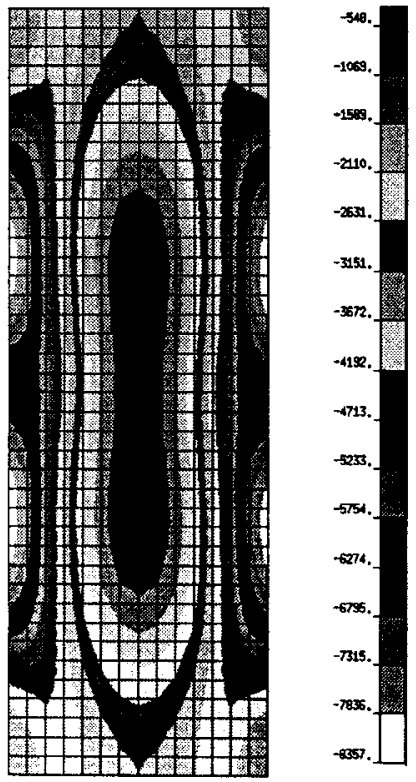

b) $\mathrm{N}_{\mathrm{x}}$ Stress Distribution
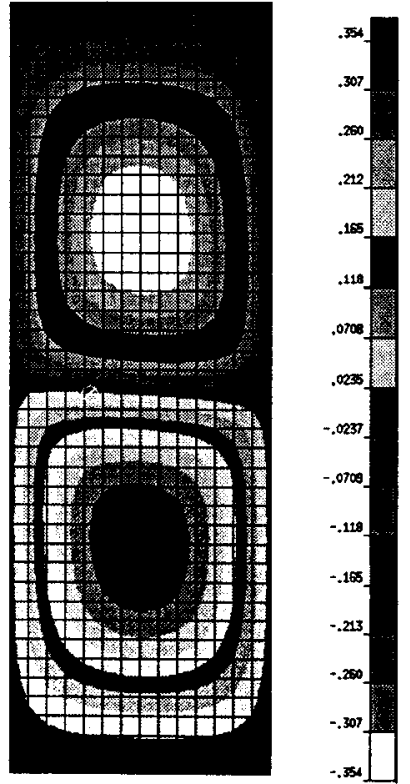

c) Out-of-Plane Deflection

Figure 11 C4 Panel: Structural Response at Final Failure (23526 lbs.) - Hashin's Criterion. 

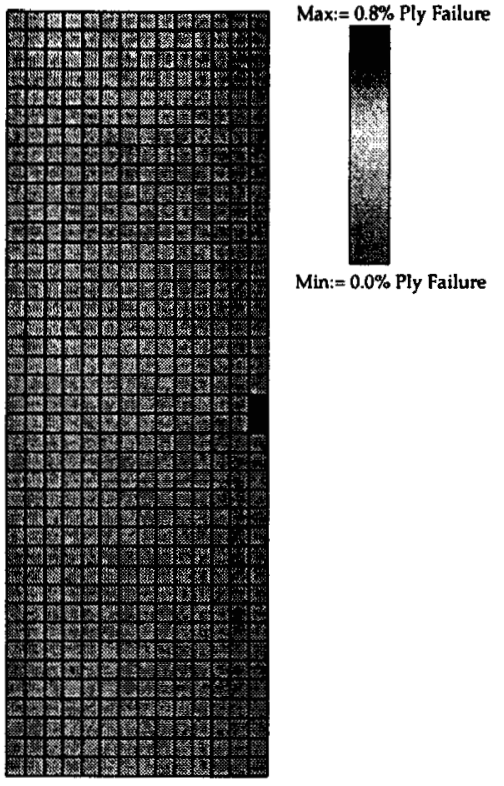

a) Percentage of Failed Plies

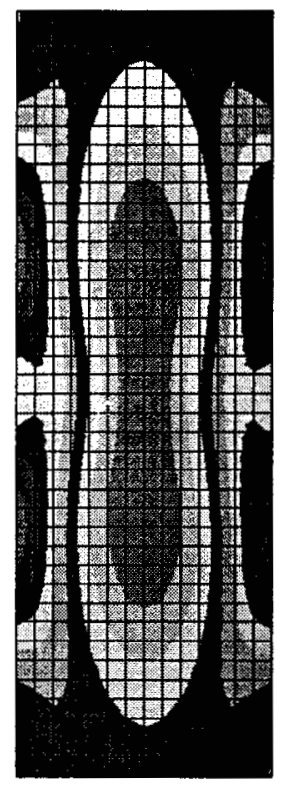

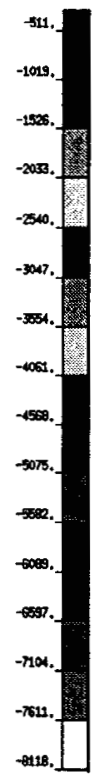

b) $N_{x}$ Stress Distribution

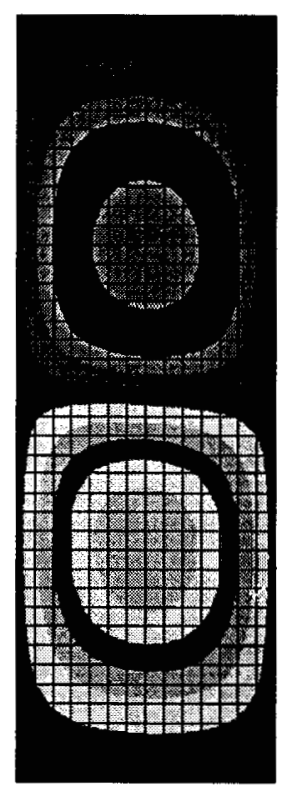

.

c) Out-of-Plane Deflection

Figure 12 C4 Panel: Structural Response at First-Ply Failure (18615 lbs.) - Christensen's Criterion.
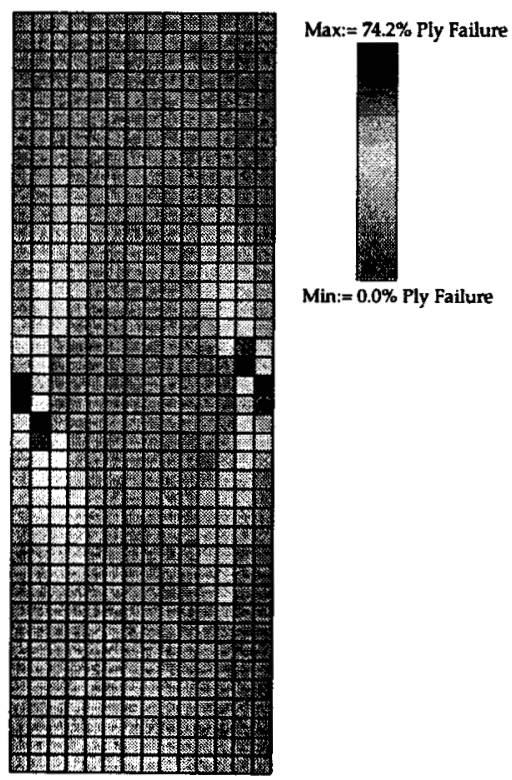

a) Percentage of Failed Plies
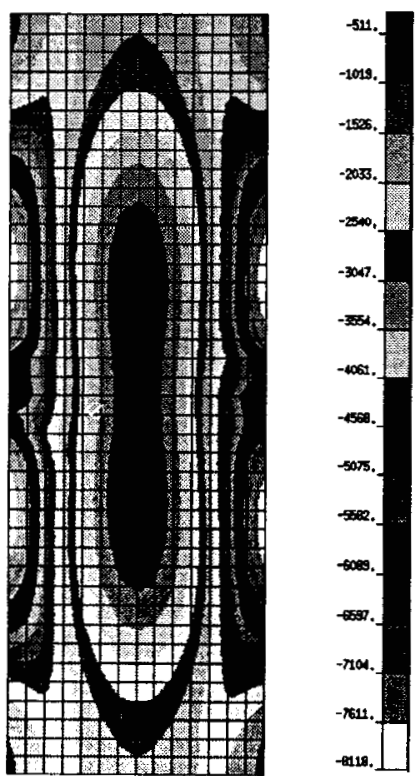

b) $\mathrm{N}_{\mathrm{x}}$ Stress Distribution
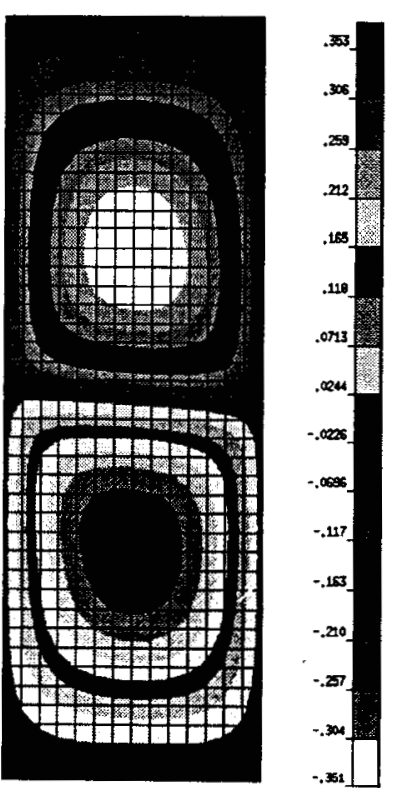

c) Out-of-Plane Deflection

Figure 13 C4 Panel: Structural Response at Final Failure (22454 lbs.) - Christensen's Criterion. 


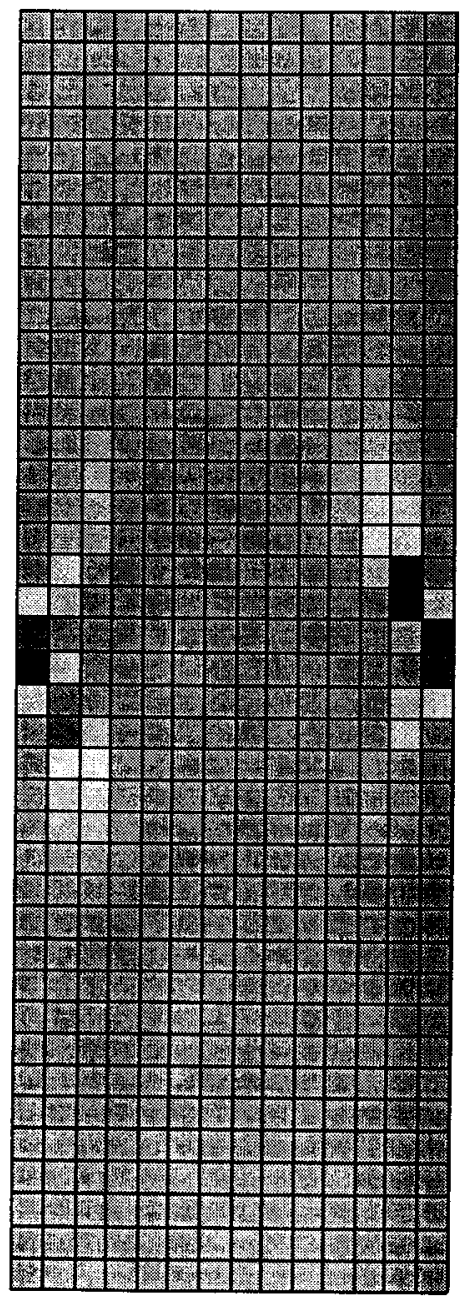

a) Percentage of Failed Plies

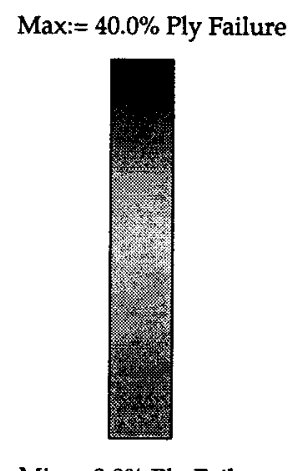

Min: $=0.0 \%$ Ply Failure

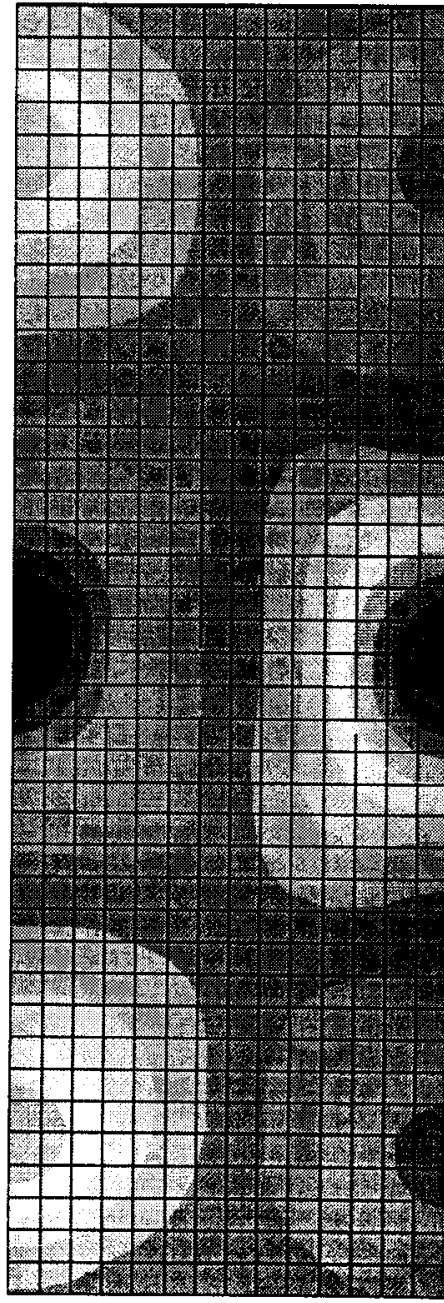

Figure 14 C4 Panel: Structural Response at Final Failure (23526 lbs) - Hashin's Criterion. 